\title{
Simulation of Teacher Interventions in a Training Course of Mathematics Teacher Educators
}

\author{
Adriana Breda ${ }^{1}\left(\mathbb{D}\right.$, Marcel Pochulu ${ }^{2} \mathbb{D}$, Alicia Sánchez ${ }^{1}$ and Vicenç Font ${ }^{1, *}(\mathbb{C}$ \\ 1 Departament d'Educació Lingüística i Literària i de Didàctica de les Ciències Experimentals i de la \\ Matemàtica, Facultat d'Educació, Universitat de Barcelona, 08035 Barcelona, Spain; \\ adriana.breda@ub.edu (A.B.); asanchezb@ub.edu (A.S.) \\ 2 Pedagogical Academic Institute of Basic and Applied Sciences, National University of Villa María, \\ Córdoba 5900, Argentina; mpochulu@unvm.edu.ar \\ * Correspondence: vfont@ub.edu; Tel.: +34-934-035-005
}

Citation: Breda, A.; Pochulu, M.; Sánchez, A.; Font, V. Simulation of Teacher Interventions in a Training Course of Mathematics Teacher Educators. Mathematics 2021, 9, 3228. https://doi.org/10.3390/ math9243228

Academic Editors: Miguel Ángel Montes and David Pugalee

Received: 25 October 2021

Accepted: 11 December 2021

Published: 14 December 2021

Publisher's Note: MDPI stays neutral with regard to jurisdictional claims in published maps and institutional affiliations.

Copyright: (c) 2021 by the authors. Licensee MDPI, Basel, Switzerland. This article is an open access article distributed under the terms and conditions of the Creative Commons Attribution (CC BY) license (https:// creativecommons.org/licenses/by/ $4.0 /)$.

\begin{abstract}
This work aimed to characterize simulated teacher interventions to manage a didactic configuration in which students solve problem situations using an ICT resource. We also aimed to identify patterns of interaction between the teacher and the students that make it possible to characterize styles of interaction and assess both their interactional and their ecological suitability. To do this, we used the tools of the Onto-semiotic Approach to Mathematical Cognition and Instruction to analyze the level of reflection of 102 educators of preservice teachers of mathematics, about hypothetical problem resolutions of their students and the types of interactions simulated by them to manage the students' learning. The educators were participants of a Teacher Training of the Teacher Specialization in Education and ICT in Argentina. The results show that there are three levels of reflection and four types of interaction (maieutic, falsificationist, dogmatic and paternalistic). We did not find a high interactional suitability in their proposals of dialogues, and participants do not consider aspects of the ecological suitability, such as the adaptation to the official curriculum. We conclude that the type of interventions that teacher educators propose is closely related to their level of reflection about the reasons why their students respond to problems in one manner or another.
\end{abstract}

Keywords: teacher educators' training; simulated teacher interventions; didactic suitability

\section{Introduction}

Historically, in the area of training of teacher educators, specific training has not been provided to become a mathematics teacher educator. Training as a teacher educator essentially happens in practice, based on the experience and exchanges with other teacher educators. Recently, this type of training has been considered as a specific area of research, with publications addressing this topic, such as the Mathematics Teacher Educator journal. Some training proposals organized specifically for these educators [1,2] have also appeared, and there has even been institutional recognition of this process in countries such as Argentina [3]. Some of these training processes include educational simulation. It is especially relevant when the training focuses on the analysis of teaching practices that aim to: (1) understand the students' mathematical activity (e.g., reconstructing the mathematical activity that students could have undertaken), and (2) simulate the management of the interaction that educators would perform to improve the students' understanding. This is the case of the Teacher Training of the Teacher Specialization in Education and ICT of the National Institute of Teacher Training, which is provided by the Education Ministry of Argentina. It was designed as a space for academic training and reflection to train teachers specialized in the pedagogical use of ICT, and to try to improve the students' educational trajectories and the institutional practices through the introduction and use of ICT.

Godino, Batanero and Font [4] present a synthesis of the Onto-semiotic Approach to Mathematical Cognition and Instruction (OSA), highlighting the problems, principles 
and methods of research in mathematics education that are addressed with this theoretical framework. Two of the addressed problems are named the Educational-instructional problem and the Problem of optimization of the instructional process.

In relation to the first problem, the theoretical system that configures the OSA includes the notion of didactic configuration [4], understood as any segment of didactic activity (teaching and learning) that happens between the beginning and the end of the process of resolution of a problem situation. Thus, this notion includes the students' and teacher's actions, in addition to the resources planned or used to address the task. Regarding the second problem, the theoretical system of the OSA includes the notion of didactic suitability, understood as a systemic criterion of optimization of a mathematics instructional process, considering the circumstances and available resources (environment). This entails the coherent and systemic articulation of six more specific suitability criteria: epistemic, ecological, cognitive, affective, interactional and mediational.

In the framework of the two problems presented above, we raise a problem: Which types of interactions among people, knowledge and resources should be implemented in the instructional processes in order to optimize learning? The context of this research is a training course directed to educators of mathematics preservice teachers of secondary school (EMPTS). We used the tools of the OSA in order to address the objective of this research: to characterize the simulated teacher interventions that teacher educators suggest to perform to manage a didactic configuration, where students solve problem situations using an ICT resource. Specifically, we searched for patterns of interaction between the teacher and the students in the simulated dialogues that make it possible to characterize styles of interaction and assess both their interactional suitability and their ecological suitability. In particular, we intended to answer these questions: Which types of simulated classroom interactions do the teacher educators propose? Do they consider the interactional suitability and the ecological suitability in their proposals of simulated dialogues?

These are relevant questions, because several authors have remarked on the didactic potential of the educational simulation in the teaching of different professions [5-7]. The students' imitation and reproduction of a certain aspect of reality that allows simulating situations similar to those they will face in their employment, facilitates the students learning progress. Moreover, it is particularly useful in the area of teacher training [8-11]. Although the knowledge and competences required by mathematics teacher educators is a relatively recent area of research [3,12-15], several authors note the didactic potential of educational simulation. In particular, it is argued that the educational simulation shows the potential of simulated dialogues to manage a classroom situation $[16,17]$ or is a means to investigate the emerging identities of preservice teachers [18]. In addition, several researchers have exposed the importance of the dialogues between teachers and students. For instance, Smith and Stein [19] state that collaborative discussions allow the students to communicate and assess their thoughts, and allow the teacher to guide these thoughts in firm mathematical directions. To do this, the teacher should select tasks that are cognitively demanding and should manage discussions using the ideas and strategies of the students in a productive way. In the case of prospective teachers, who do not work at school and perhaps cannot implement the activities they created, the educational simulation of dialogues is necessary for enable them to imagine what could happen in the classroom when the designed activities are implemented.

\section{Theoretical Framework}

Godino et al. [4] explain that one of the problems that the OSA addresses is the Educational-instructional problem. The main questions related to this problem are these: What is teaching? What is learning? How are they related to each other?

In the model of instruction (understood as a relation between the teaching and learning of a certain content) that OSA assumes, the "zone of proximal development" plays a key role. This leads to the acceptance of the following specific principles: (1) The purpose of learning is the students' appropriation of the institutional meanings and objects that 
enable them to solve certain problems and develop as a person. (2) The study of the students' personal meanings is an essential component of the Educational-instructional problem, because the appropriation of intended institutional meanings is conditioned by the initial personal meanings of the students.

In the OSA, the notion of didactic configuration is the main methodological tool for the analysis of instructional processes at the micro level [20]. It is defined as any segment of didactic activity (teaching and learning) that happens between the beginning and the end of the process of resolution of a problem situation. Therefore, it includes the students' and the teacher's actions, in addition to the resources planned or used to address the task. There are four types of theoretical configurations, namely, magisterial, adidactical, personal and dialogical configurations. The adidactical configuration is a sequence of adidactical situations of action, formulation, validation and the didactic situation of institutionalization. The traditional or classical way of teaching mathematics based on the master class, followed by the resolution of some exercises, characterizes the magisterial configuration. When the student solves the task without a direct intervention of the teacher (for instance, solving exercises that the teacher proposed out of the classroom), the type of didactic configuration is one in which the personal study predominates. Other types of configuration can be defined respecting the moment of exploration of the students, but with the teacher assuming the validation and institutionalization through a contextualized dialogue between the teacher and the students. The empiric didactic configurations that happen in reality are more or less close to these theoretical configurations. The sequence of didactic configurations forms a didactic trajectory of teaching and learning.

In any didactic configuration, there are three components: (a) an epistemic configuration, (b) an instructional configuration and (c) a cognitive-affective configuration. The epistemic configuration is the system of institutional mathematical practices, objects and processes that the task requires. The instructional configuration is the system of functions of the teacher and the students, the instructional means that are used, and the interactions between the different components. The cognitive-affective configuration is the system of personal mathematical practices, objects and processes that describe the learning and the affective components that accompany it. In the instructional configuration, the interactionunderstood as an action, relation or mutual influence between two or more people or things in the teaching and learning process-is a relevant factor to facilitate (or not) the students mathematical learning [21]. Although there are many types of interaction, there is a general agreement that a type of interaction that enables any participant to express their opinions, convictions and suggestions (related to the task and knowledge that are the object of the interaction), and to try to convince others of the validity of their ideas, should be enhanced in the instructional processes. Moreover, teachers should have the competence to develop this type of interaction and show it in their management of the instructional processes that they implement. Thus, this competence should be developed in the processes of teacher training. This gives rise to the following question that motivates this research: Which types of interactions between people, knowledge and resources should be implemented in the instructional processes to optimize learning?

The last question is included in a more general question: Which type of actions and resources should be implemented in the instructional processes to optimize the mathematical learning? The OSA intends to answer this question with the notion of didactic suitability, assuming that the didactic knowledge helps to generate principles that guide the teacher's practice and its improvement. In the theoretical system of the OSA, the notion of didactic suitability is included as a systemic criterion of optimization of a mathematics instructional process. Didactic suitability is the degree to which this process (or a part of the same) has certain characteristics considered as optimal or adequate for succeeding in the adaptation between the students' personal meanings (learning) and the intended or implemented institutional meanings (teaching), regarding the circumstances and available resources (environment). This entails the coherent and systemic articulation of six dimensions: epistemic, ecological, cognitive, affective, interactional and mediational. Attaining a high 
didactic suitability requires a balance among the partial criteria of the different dimensions considering the context [22]. The suitability corresponds to some changing circumstances of time and context, which requires that the teacher has an attitude of reflection and investigation. It entails the acceptance of an axiological rationality in mathematics education that enables the analysis, the review, the justification of the choice of means and purposes, the justification of the change, and the answer to this generic question: Which aspects can be addressed in order to progressively improve the mathematics instructional processes?

The notion of suitability is concretized in criteria, components and indicators. Table 1 shows the components and indicators of the interactional suitability and ecological suitability criteria, adapted from [23], which were considered in this research.

Table 1. Components and indicators of interactional and ecological suitability.

\begin{tabular}{|c|c|}
\hline Components & Indicators \\
\hline \multicolumn{2}{|r|}{ Interactional suitability } \\
\hline $\begin{array}{l}\text { Teacher-students interaction } \\
\text { (IS1) }\end{array}$ & 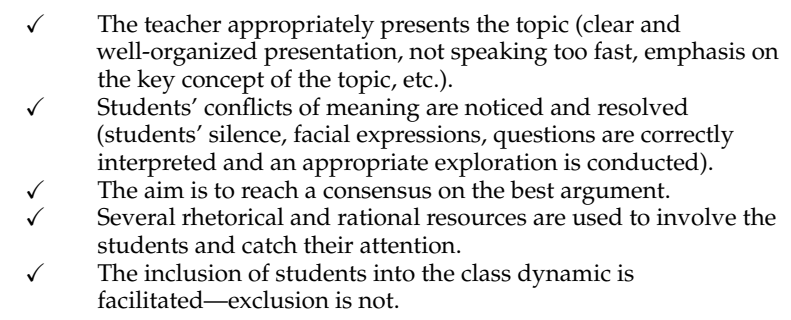 \\
\hline Interaction among students (IS2) & $\begin{array}{ll}\checkmark & \text { Dialogue and communication between students is encouraged. } \\
\checkmark & \text { Inclusion in the group is enhanced and exclusion is discouraged. }\end{array}$ \\
\hline $\begin{array}{l}\text { Autonomy } \\
\quad \text { (IS3) }\end{array}$ & $\begin{array}{l}\text { Moments in which students take on responsibility for their } \\
\text { study (exploration, formulation and validation) are observed. }\end{array}$ \\
\hline $\begin{array}{l}\text { Formative assessment } \\
\text { (IS4) }\end{array}$ & Systematic observation of the cognitive progress of the students. \\
\hline \multicolumn{2}{|r|}{ Ecological suitability } \\
\hline $\begin{array}{l}\text { Adaptation to the curriculum } \\
\qquad \text { (EcS1) }\end{array}$ & $\begin{array}{l}\text { The content, its implementation and evaluation, correspond to } \\
\text { the curricular plan. }\end{array}$ \\
\hline $\begin{array}{l}\text { Intra/interdisciplinary connections } \\
\text { (EcS2) }\end{array}$ & $\begin{array}{l}\text { Contents are related to other mathematical topics (connection of } \\
\text { advanced mathematics with curricular mathematics and the } \\
\text { connection between different mathematics content covered in } \\
\text { the curriculum) or to the content of other disciplines, (an } \\
\text { extra-mathematical context or links with other subjects from the } \\
\text { same educational level). }\end{array}$ \\
\hline $\begin{array}{l}\text { Social and labor usefulness } \\
\text { (EcS3) }\end{array}$ & The course content is useful for social and labor incorporation. \\
\hline $\begin{array}{l}\text { Didactic innovation } \\
\quad \text { (EcS4) }\end{array}$ & $\begin{array}{l}\text { Innovation based on reflective research and practice } \\
\text { (introduction of new content, technological resources, methods } \\
\text { of evaluation, classroom organization, etc.). }\end{array}$ \\
\hline
\end{tabular}

rSource: Breda et al. [23].

Components and indicators of didactic suitability criteria (DSC) are defined based on the current trends in mathematics teaching, the principles of NCTM [24] and the results from research in Mathematics Education that rely on a wide consensus among professionals in the area. For instance, the research results that evidence the importance of autonomy in the students' learning are considered in the interactional suitability. The component autonomy derives from these results and it proposes to enhance the students' autonomy in the teaching and learning process as a guideline that teachers should follow in the design and redesign of the learning sequences. 
The DSC and their components and indicators constitute a consensual tool, which is used to structure teachers' reflection in teacher training programs in Argentina, Brazil, Chile, Costa Rica, Ecuador, Mexico, Panama and Spain [25-27]. Before the implementation, DSC guide the teachers about how they should undertake the implementation and, after it, DSC are useful to assess the implemented teaching and learning process.

Seckel and Font [2] describe research on the development of reflexive competence in a mathematics teacher educator. They describe the training cycle to develop this competence. In the first phase of this cycle, the teachers present a classroom episode to the participants and ask them to opine, without giving them any guidelines for their reflection on the episode. The authors observe that: (1) most of the participants value the teacher's management of the interaction negatively, because they think that it excludes some students; and (2) they propose simulated interactions between the teacher of the episode and the students to avoid their exclusion. That is, participants consider the principle of not excluding students (an indicator of the component of teacher-student interaction of the interactional suitability criterion) to guide the teacher-student interaction. More generally, the results show that the didactic suitability criteria are a useful methodological instrument that promotes and supports educator's reflection on practice, because they enable attention to be drawn to the most important aspects of learning episodes.

In addition, DSC have been also used as a priori categories to infer patterns that guide the teachers' practice, when they do not know this tool [28]. In this line, Arceo et al. [17] report research whose aim is to identify the criteria used by an educator of primary school teachers when he reflects on his practice. Their research is a case study in which they use the didactic suitability to perform qualitative analysis of both the classroom observations and the educator's comments about the classroom in a subsequent interview. It is noteworthy that the teacher educator implicitly uses some of the components and indicators of DSC, emphasizing the interactional, the cognitive, the epistemic and the mediational criteria, and, to a lesser extent, the ecological criterion. This educator considers that making the preservice teachers of primary school aware of the importance of an appropriate management of the classroom is a key aspect in the teacher training. To do this, the educator thinks that the preservice teachers should have a space for simulation of a classroom of a primary school (moments when the preservice teachers take the role of primary school students and moments when they take the role of the teacher). Moreover, the educator intends that his model of classroom management be a reference for his students.

\section{Materials and Methods}

This study is part of more general research in a context of design, implementation and redesign of training courses for educators of preservice mathematics teachers of secondary school, organized by the educational administration of Argentina. The aim of the general research was to determine how the process of building a sequence of professional tasks performed by the participants affects the development of their didactic analysis competence [3]. We used a methodology that includes elements of design-based research [29]. In particular: (1) The experience happens in a natural context (a training course for educators of mathematics teachers of secondary school); (2) we intended that the design, the implementation and the research were interdependent; and (3) we considered the following phases: (a) preparation of training course design; (b) course implementation; (c) retrospective analysis of the data generated during the implementation. It is also design research based on the use of some tools of the Onto-semiotic Approach [4]. First, the design of the training cycle acted as a context of research. Second, the continuous analysis performed, together with a retrospective examination, provided information to redesign and improve the training cycle.

\subsection{Context}

Teacher Training of the Teacher Specialization in Education and ICT (TSET) of the National Institute of Teacher Training (NITT), which is provided by the Education Ministry 
of Argentina, was designed as a space for academic training and reflection to train teachers specialized in the pedagogical use of ICT. At the same time, this training tries to improve the students' educational trajectories and the institutional practices through the introduction and use of ICT. TSET is a postgraduate degree that lasts two years $(400 \mathrm{~h})$ and uses a mixed learning model, with virtual sessions ( $70 \%$ of the total) and face-to-face sessions ( $30 \%$ of the total) offered in different areas of knowledge, in particular, in Mathematics. TSET has an introduction module where participants become familiar with the virtual environment. In addition to this introduction module, TSET has 7 more modules and 2 intensive seminars.

One of these modules, named Module of Development of Educational Proposals with ICT 1 , offers some theoretical and practical elements that enable the educators to develop their competences of design and didactic analysis of learning activities with ICT. Moreover, the core of this module is the analysis and design of activities for the classroom of Mathematics for the High Level, where ICT provides essential resources for teaching and learning. Therefore, the teachers of this module-educators of educators of preservice teachers of mathematics of secondary school (EEMPTS) —introduce to the participants-educators of preservice teachers of mathematics of secondary school (EMPTS)—some guidelines for the design of tasks and interventions to manage the classroom, according to the curricular designs of Argentina and to the current trends in Mathematics Education. In order to elaborate these guidelines, the teachers of the module considered the didactic suitability criteria (DSC).

\subsection{Participants}

The participants were 102 educators of preservice teachers of mathematics that took the Module of Mathematics for TSET. The participants correspond to the total number of participants who took the TSET course. These educators work in Institutes of Teacher Training in Argentina and they know some theoretical areas and approaches of Mathematics Education, in particular, the Theory of Didactical Situations, as they mentioned in the forum of the presentation of the course.

\subsection{Data}

In this study, we only present the analysis of the data corresponding to one of the activities of the course (the final assignment of the module). In this task, the teacher educators had to, first, create a problem or select it (or adapt it) from a list of problems. An example of the type of problem that they should create or select, suggested as an example by the teacher of the module, was this: Let $\mathrm{f}: \mathrm{R} \rightarrow \mathrm{R}$, with $f(x)=a x^{2}+b x+c$, where $a, b$ and $c$ are real numbers. Describe the graphical characteristics of the family of curves that result from the variation of only parameter $b$.

Once the problem was selected, adapted or created, participants should justify whether the problem fits the following guidelines of problem design, which were previously explained in the module:

$\checkmark \quad$ The task should not be closed; more than one resolution strategy should be possible. This way, the same task can generate different types of students' mathematical activity and it is useful to compare the different resolution strategies in a discussion that allows for the elaboration of connections between the strategies (one of the indicators of mathematical richness of the curriculum).

$\checkmark \quad$ The task should not suggest possible strategies, results to apply, etc.

$\checkmark \quad$ The task should not provide many guidelines. If the task is guided with many questions, relevant processes such as conjecturing, validation, etc., does not happen. It is better that the task has less questions (general questions) and the students undertake a process of analysis, which leads them to solve intermediate questions.

$\checkmark \quad$ The task should require that the students justify their choices, in addition to the ideas that they reject. It should enhance a relevant mathematical process, i.e., argumentation. 
$\checkmark \quad$ If the context of the task is a real context, it should be meaningful and relevant when solving the task; that is, avoid posing questions where the context is a trivial "scenery". This prevents the student from thinking that the teacher's intention focuses on the mathematical objects instead of focusing on the interest of the problem in its context.

$\checkmark \quad$ As far as possible, avoid giving information that assures the existence and/or uniqueness of the solution of the task.

$\checkmark \quad$ Consider the introduction of some instructions that make the students reflect on their own activity to solve the task. This meta-reflection on their own activity should be achieved with diverse instructions: compare different solutions, reflect on the strategies that were not useful, make connections with other mathematical concepts, etc.

$\checkmark \quad$ The use of new resources should be necessary to solve the task. For instance, these resources could allow for the application of certain techniques, or the drawing of certain graphs or figures that would not be possible without this technology.

$\checkmark \quad$ The task should ask about some mathematical object, not something related to the use of the software. The aim is to teach mathematics and not only the use of a single software package or certain commands.

For instance, we can justify that the previous problem about the characteristics of the parabolas (the example suggested by the teacher of the module) fits the second guideline because it is an open-ended problem that does not suggest any strategy of resolution.

Third, the participants should propose some possible (correct or wrong) answers that their students (preservice teachers) would give as a solution to the problem. In the case of the problem of describing the characteristics of the parabolas, the students should be able to use a dynamic geometry software package to explore and make conjectures that they would try to validate in this learning environment. In order to illustrate this step, the teacher of the module proposed an example with the following conjectures, which were elaborated by a group of preservice teachers when they solved the problem of describing the characteristics of the parabolas:

i. If $b$ is positive, the increasing branch of the parabola intersects the ordinate axis, and, if $b$ is negative, the decreasing branch of the parabola intersects the ordinate axis (Figure 1).



Figure 1. Graphs of the second-degree functions of conjecture i.

ii. As $b$ decreases, the parabolas become bigger (Figure 2). 


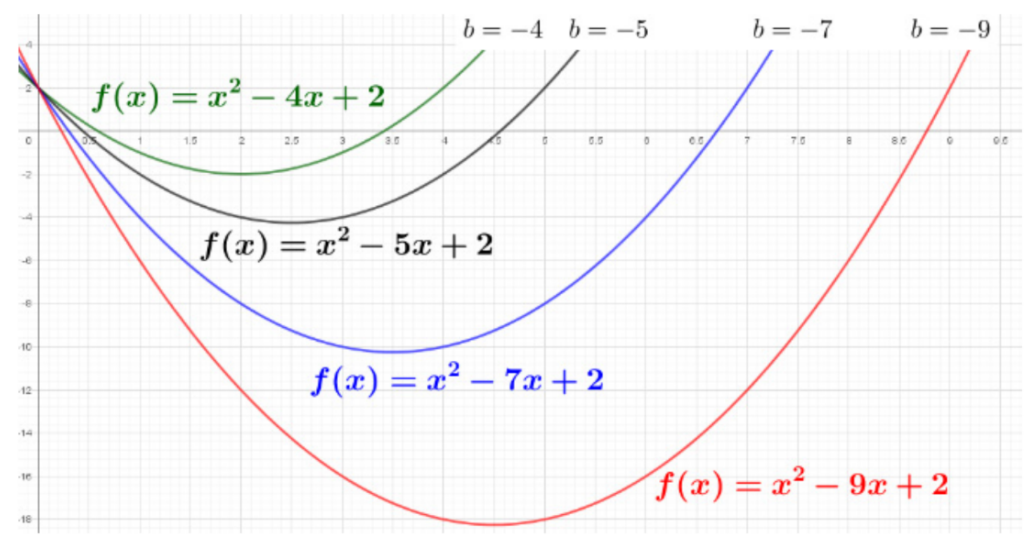

Figure 2. Graphs of the second-degree functions of conjecture ii.

iii. If $a$ and $b$ have the same sign, the vertex of the parabola is on the left side of the ordinate axis. If $a$ and $b$ have different signs, the vertex is on the right side of the y-axis.

iv. The vertexes of the family of parabolas of the form $y=a x^{2}+b x+c$, describe a geometric locus, which is other parabola with equation $y=-a x^{2}+c$.

$\mathrm{v}$. If $b$ is negative, the parabola is on the left side of the ordinate axis and, if $b$ is positive, the parabola is on the right side of the axis.

vi. If $b$ is negative, the parabola is on the right side and, if $b$ is positive, it is on the left side.

vii. The parameter $b$ causes shifts of the parabola, but this depends on the sign of the parameter $a$.

viii. As $b$ decreases, or increases, the parabola moves down.

In this third step, the educators should also reflect on the reasons why their students (preservice teachers) answer the problems one way or another.

Finally (the fourth step), participants should select a hypothetical answer and explain how they would intervene to lead the students (preservice teachers) to the learning resulting from their activity. These interventions should be presented in the form of a simulated dialogue between the teacher and the students. To do this, the educators should consider the following guidelines [3]:

$\checkmark \quad$ Consider moments of noticing in advance possible errors, unexpected answers, inactivity, etc. in each task and anticipate appropriate teacher interventions. Express this in the form of a dialogue, avoiding vague descriptions.

$\checkmark \quad$ Avoid giving more information than strictly necessary.

$\checkmark \quad$ Intervene based on what the student presents, trying to identify what and how he/she thinks. Avoid leading the student to the solution that the teacher thought. Somehow, the cognitive conflict (in terms of Piaget) should appear in order to give the students the opportunity to achieve a solution on their own.

$\checkmark \quad$ If several resolutions and errors do not appear, intervene, asking the students for arguments about the validity of the conjectures and procedures that other classmates applied to solve the same problem (for instance, interventions such as "The students of the other class say that it is correct to do.").

$\checkmark \quad$ Avoid directly saying if the resolution is correct or not. Instead, ask for explanations to try to understand the way of thinking that led the student to come up with that answer.

$\checkmark \quad$ Consider that it is not necessary that only one intervention of the teacher solves the student's question and postpone the resolution of the doubt in later interventions. For instance, broaden the doubt, pose new questions or remind of previous strategies.

$\checkmark \quad$ Avoid asking for explanations only when the answer is wrong; also ask for explanations when the answer is correct. These explanations can uncover a wrong argument that the student used to achieve a correct solution, following an inaccurate process. 
Due to the characteristics of the task that the teacher educators should undertake, some guidelines related to the component "autonomy" and the indicator "Students' conflicts of meaning are noticed and resolved (students' silence, facial expressions, questions are correctly interpreted and an appropriate exploration is conducted)" of the component "teacher-student interaction" of the interactional suitability criterion were proposed. However, no explicit guidelines for the ecological suitability criterion were provided. Therefore, participants should create a narrative of a simulated classroom interaction following these guidelines.

An example of such a simulated dialogue proposed by a participant and related to the problem of determining the characteristics of the parabolas (lines 369-387), was this:

1. Student: If $b$ is positive, the increasing branch of the parabola intersects the ordinate axis, and, if $b$ is negative, the decreasing branch of the parabola intersects the ordinate axis.

2. Teacher: Step by step. When $b$ is positive, does the increasing branch of the parabola always intersects the ordinate axis? How did you get this conclusion?

3. Student: Looking at the graphs of $y=x^{2}+3 x+1, y=x^{2}-3 x+1, y=-x^{2}+3 x+1$; $y=-x^{2}-3 x+1$ with the branches facing up, $b$ is positive and negative; and other example with the branches being negative. It works for all these cases.

4. Teacher: Will it always work? Now try to find a parabola with positive $b$ but with its decreasing branch intersecting the y-axis.

5. Student: Teacher, I can't find it. I used a slider for $b$ and then I studied the graphs of $y=x^{2}+b x+1$ and of $y=-x^{2}+b x+1$ and their increasing branches intersect the $y$-axis.

6. Teacher: Let's try to elaborate some explanation. Consider the functions of the form: $y=a x^{2}+b x+c$, with positive $b$. Which are the values of $x$ for increasing the function? How can we know if this branch intersects the y-axis?

7. Student: Should it be $x=0$ in this interval?

8. Teacher: Ok, try to make an explanation for your classmates.

\subsection{Data Analysis}

In order to answer the first question of this study (Which types of simulated classroom interactions do the teacher educators propose?), first, we focused on the analysis of the data corresponding to the third step (level of reflection of the participants about the answer that they would give to their students). For this step, we used inductive categories. For example, one participant of the course proposed the following problem:

Given a convex quadrilateral, four triangles are determined by drawing the diagonals of the quadrilateral. Is it possible that their areas, assigned in a certain order, were four consecutive whole numbers? When solving this problem, justify the procedures that you perform. Is the answer that you obtain unique? How would you justify it?

She also reflected on how her students (preservice teachers) would answer:

I have observed that, generally, when I mention a quadrilateral, they tend to focus on a certain quadrilateral, usually a square, or a rectangle. They rarely think of a parallelogram or a trapezium. It is even rarer when they think of a general convex quadrilateral, meaning a trapezoid. From this restricted view, I think that they would start drawing the chosen quadrilateral, probably with a software such as GeoGebra, since I use it with my students. Their analysis begins this way, the answer that they obtain will not be the final answer to the problem, because they will find possible relations between the areas of certain triangles, but it would boost new questions and stimulate the students to find new answers.

In this paragraph, we observed that the teacher educator explored the answers that she thought that her students would propose in detail and thoroughly. For this type of answer, 
the category A1 (A1: Participants that explore in detail what the student could have done) inductively emerged.

However, another participant explained the following, when she reflected on possible answers of her students to the problem that she had proposed:

In this activity, most of the difficulties can appear in the construction of the model that allow for estimating results considering the graphics as a starting point, until obtaining a polynomial fitting of the data that represents reality. Thus, we can collaborate with the principal of the high school.

In this case, the teacher educator did not explore in detail what the students could do and she only talked about general difficulties that the students may face in understanding the task. Because this reflection did not correspond to category A1, we generated a new category (A3: Participants that focus on the difficulties of the student to understand a task, use inappropriate vocabulary, judge the answer of a student as not acceptable, or express that it is not possible to know what the student did).

Then, we focused on the fourth step (related to the simulated dialogues). For this step, we used some a priori categories, namely, the general types of didactic configurations [21], which were subcategorized with inductive categories that emerged from data. For example, a simulated dialogue, proposed by a participant and related to the problem of determining the characteristics of the parabolas (lines $426-442$ ), was this:

1. T: Which values did you consider for $a, b$ and $c$ ?

2. S: $a$ and $c$ are positive and I changed $b$. I tried these values: $a=1, c=2$ and for $b$ I tried with 2 and $-2,4$ and $-4, \frac{1}{2}$ and $-1 / 2,3$ and $-3,9$ and -9 . In addition, the graphs go through the point with ordinate two.

3. T: Is this a common point by chance?

4. S: No, it isn't; because when I changed the value of $c$, the increasing or decreasing branch of the graph intersected the ordinate axis at that value.

5. T: Was this the only thing that you changed?

6. S: Yes, for now.

7. T: (Comment) Give (the student) some time so that (the student) can try other values and see it again. If (the student) did not do it, and it can happen, for example ...

8. S: Teacher, I changed the value of $a$ to a negative number and the curve inverts, but the branches intersect the axis at the value of $c$ as well.

9. T: What do you think if you try other changes? (Teacher's comment: this last question intends to suggest that the student continues trying and looks for other variations. For instance, changing $a$ to see the widening or narrowing of the curve depending on the different values of $a$ ).

This dialogue corresponds to one of the categories considered a priori (it is a didactic configuration of the dialogical type). In addition, because it is a dialogue in which the teacher tries to encourage the student to refute the conjecture, which did not happen in other dialogues of the dialogical category, we considered the category of falsificationist dialogue as an emergent inductive category.

We looked for categories that coherently grouped several of the actions and reactions of the teacher to the interventions of the students. Some of these actions and reactions are approving or disapproving the student's intervention; repeating relevant content of the intervention with the same or different words; rewording (relevant content) with equivalent forms or ideas; redirecting the knowledge shown in the student's interventions; exploring and broadening the intervention; stressing a question or intervention; and returning reflections from the student's intervention to other students or to the whole group ([30] p. 12). Thus, we did not focus on one-time reactions of the teacher, such as revoicing [31].

In order to answer the second question (Do educators consider the interactional suitability and the ecological suitability in their proposals of simulated dialogues?), we mainly used a content analysis methodology, which has been previously used by other authors in the 
framework of the OSA [32,33]. We tried to find a text that could be considered as evidence of the implicit use of some indicators or components of a didactic suitability criterion (deductive categorization). This means that, in this phase of analysis, DSC (in particular, the components and indicators of the interactional and ecological suitability criteria) were considered as previous categories to analyze the teachers' discourse. For example, the following paragraph, proposed by a teacher educator in his final assignment of the module, was considered as evidence of the implicit use of the component IS2 of the interactional suitability (interaction among students):

Groups of three or four students, depending on the number of available notebooks, are preferred to other types of groups, since they allow for flexible and productive dynamics from the participation of all the members of the group and allow the group to work in an appropriate environment.

This is another example of evidence of the implicit use of the component IS4 of the interactional suitability (formative assessment) by an educator: "The responsible teacher will sound out the work that students are doing and will conveniently participate with guiding questions in order to maintain the level of activity in the classroom, without losing sight of its objective."

We validated the categories with a data triangulation. For this triangulation, we used the reflection of the participants on the answer that they would give to their students, the simulated dialogues and the text that could be considered as evidence of the implicit use of some indicators or components of a didactic suitability criterion. We also undertook a triangulation between the authors of the article. Each author related a dialogue to one of the categories considered a priori (for instance, the didactic configuration of dialogical type). In addition, each author assigned an emergent inductive category and then reached an agreement.

\section{Results}

To answer the first question (Which types of simulated classroom interactions do the teacher educators propose?), we performed an analysis of the data from step 3 (participants' reflection on the answers that students would give) and the data from step 4 (simulated dialogues). In relation to step 3, three levels of reflection were inferred. These levels allow for the classification of the participants into three groups (from more to less reflection):

A1: Participants that explore in detail what the student could have done. In this category, we gathered 35 of the 102 participants (34.31\%). Some of the teacher educators of this group will reflect on real answers, and not simulated answers of their students. For instance, an educator posed this problem to her students (mathematics preservice teachers of secondary school):

A not so well-known center of a triangle $a b c$ is the excenter, which is the intersection of the lines that contain the lines that bisect the exterior angles corresponding to two angles of the triangle. Given the properties of the triangle $a b c$, what can you say about the excenter?

From the answers of her students, she reflects that the preservice teachers proposed some properties that had not been considered in the previous analysis and other expected properties were not developed:

To sum up, three groups began working with the line that bisects the opposite angle (one of them included the incenter in the analysis). Two groups began working with the sides of the original triangle and the triangle formed by two vertexes of the triangle and the excenter. The other group focused on the angles of the triangle formed by the excenters ( ... ).

A2: Participants that speculate and think on "perhaps the student could do ... ", but they do not explore or verify the possible answer that a student would give. In this category, we grouped 31 of the 102 participants (30.39\%). For instance, regarding the problem of the 
characteristics of the parabola, an educator considered the conjecture that he supposed that a student would do (if $b$ is positive, the increasing branch of the parabola intersects the ordinate axis, and, if $b$ is negative, the decreasing branch of the parabola intersects the ordinate axis). The participant explained that perhaps the student could not analyze other possibilities with which they could have discovered that the hypothesis was wrong, because, if $b$ is negative, the increasing branch of the parabola intersects the ordinate axis in some cases.

A3: Participants that focus on the difficulties of the student to understand a task, use inappropriate vocabulary, judge the answer of a student as not acceptable, or express that it is not possible to know what the student did. In this category, we grouped 36 of the 102 participants (35.29\%). For instance, regarding the problem "The perimeter of the rectangle of the figure is $20 \mathrm{~cm}$. Determine the value of $x$ and then the area of the rectangle", the educator explained that it is possible that some students (most of them) have difficulties with the use of the suggested software, especially with the sentences of the proposed graphs:

In relation to the observations and conclusions, it is possible that the students find it difficult to colloquially and symbolically express them. It is also probable that some students (though a small number) have difficulties with the calculus of the areas and perimeters, considering the set of real numbers. It is probable that some students do not achieve planned objectives.

Regarding the interventions that the educators propose, the following types of interventions were inferred:

I1: Participants that propose some questions to the students considering what the students have undertaken in order to make them reflect on their activity. This type of intervention is divided into two types of interventions. The first one follows a maieutic style; the teacher poses questions so that the students achieve knowledge through their own conclusions and not through a learned content. The second type follows a falsificationist style; the purpose of the teacher's interventions is to refute a conjecture with a counter example or suggesting the exploration with more particular cases.

I2-I3: Participants that propose some questions to make the students reflect, but ignoring what they have done (I2) and/or suggesting the way that they should follow (I3). In both cases, the teacher follows a paternalistic style, because the interventions entail a reduction in student's liberty and autonomy, because the teacher suggests the way to complete the task.

I4: Participants that ignore what the students did and only give orders to make the students follow the way that the teacher wants, even discrediting true unexpected conjectures. This style of intervention could be considered dogmatic, because the educator proposes interventions that ignore what the student has done to propose the way that the teacher thinks should be used to solve the task.

The first type of intervention (I1) corresponds to a dialogical didactic configuration; whereas the last (I4) corresponds to a magisterial configuration. I2 and I3 have aspects of a dialogical configuration, although they are not exactly this type of configuration, because there is some dialogue, but the teacher does not pay much attention to the student.

In the following, we present two examples of dialogues (maieutic and dogmatic) related to this problem: How many matches are necessary to make the figure in position thirty? (The figure in position thirty is the term 30 of an exercise to find a pattern made with matches. The term 1 is one hexagon made with six matches. The term 2 is two hexagons with one side, one match, in common. Each term is built adding one hexagon that shares one side with the hexagon added in the previous term.) With these possible solutions:

i. The number of matches is equal to the number of the figure times 6 ( $m=6 n$, where $\mathrm{m}$ is the number of matches and $\mathrm{n}$ is the number of the figure).

ii. The number of matches is equal to the number of the figure times 6, minus the matches in common, which is the number of the figure minus one $(m=6 n-(n-1))$. 
iii. The number of matches is equal to the number of the figure times 6 , minus the matches in common $(m=6 n-n)$.

iv. The number of matches is equal to 5 times the number of the figure, because hexagons share a match $(m=5 n)$.

v. The number of matches is equal to 6 plus 5 times the number of the figure minus one $(m=6+5(n-1))$.

This is a simulated dialogue (lines 565-577) of a teacher educator that exemplifies the type of intervention I1 of a maieutic style, in relation to conjecture (iv):

1. T: How did you get to the result?

2. S: We saw that each figure has 5 matches, because they share one, then we multiplied 5 times 30. This gave us 150 .

3. T: I understand it, and how could we notice that 150 matches are enough to make the Figure 30 and there are not matches left?

4. S: We should verify the result, drawing the figure and counting the matches.

5. T: Sure, I understand you. Now, if you had to explain to other classmate your counting strategy, what would you say?

6. S: Multiply 5 times the figure that should be drawn.

7. T: Then, if I have to draw Figure 2, how many matches would I need?

8. S: (Looks at the term 2) Eleven matches.

9. T: How many matches would we need if we use your strategy?

10. S: Something is wrong! I will think on it again and then I'll tell you.

This is a simulated dialogue (lines 580-593) of a teacher educator that exemplifies the type of intervention I4 of a dogmatic style, in relation to conjecture (iv):

1. T: How did you get to this result?

2. S: We saw that the figures were formed by hexagons that have 6 sides, but they share one match. Then, only five matches are necessary to do the hexagon, that's why we multiplied 5 times 30, this is 150 .

3. T: But, why didn't you count the number of hexagons and then subtract the number of matches in common? This way is easier!

4. S: Do we subtract the 30 matches that are in common?

5. T: No, there are 30 matches in common! In Figure 2, how many matches are shared?

6. S: One.

7. T: And in Figure 3?

8. S: Two.

9. T: Well, there are not 30 matches in common. Check the strategy and then we will see it.

If we consider the analysis of step 3 and perform a data triangulation with the simulated interventions proposed by the teacher educators (step 4), we obtain the relations of Figure 3.

\begin{tabular}{cc}
\hline $\begin{array}{c}\text { Level of } \\
\text { reflection of the } \\
\text { educators }\end{array}$ & $\begin{array}{c}\text { Number of } \\
\text { educators }\end{array}$ \\
\hline A1 & 12 \\
A1 & 23 \\
A2 & 19 \\
A2 & 12 \\
A3 & 2 \\
A3 & 8 \\
A3 & 26 \\
\hline
\end{tabular}

\begin{tabular}{ccc}
\hline & $\begin{array}{c}\text { Number of } \\
\text { educators }\end{array}$ & $\begin{array}{c}\text { Type of } \\
\text { intervention }\end{array}$ \\
& 12 & $\mathrm{I} 1$ \\
$\longrightarrow$ & 23 & $\mathrm{I} 3$ \\
$\longrightarrow$ & 19 & $\mathrm{I} 3$ \\
$\longrightarrow$ & 2 & $\mathrm{I} 2-\mathrm{I} 3$ \\
$\longrightarrow$ & 12 & $\mathrm{I} 2$ \\
$\longrightarrow$ & 26 & $\mathrm{I} 4$
\end{tabular}

Figure 3. Relations between the levels of reflection of the participants on the answers that they suppose that students would give and the types of simulated interventions proposed by them. 
In relation to the second question (Do educators consider the interactional suitability and the ecological suitability in their proposals of simulated dialogues?), it is significant that, despite the fact that specific guidelines were proposed to achieve a high level of students' autonomy (a component of the interactional suitability criterion), their simulated dialogues, in many cases, did not consider this aspect. This is the case of the following example (related to a conjecture of the problem of describing the characteristics of the parabolas), where we can observe that the proposed interventions entail a reduction in the student's liberty and autonomy, since the teacher suggests the way to solve the task (lines 608-619):

1. Teacher: Why did you consider $c=0$ ?

2. Student: Because I formulated that the shift of $b$ depended on the value of $a$.

3. Teacher: Does the task establish any condition for the parameters?

4. Student: Yes, they should be real numbers.

5. Teacher: And what did you choose for $a$ and $b$ ?

6. Student: Only whole numbers.

7. Teacher: And does the task ask for this?

8. Student: No, but I thought that it was easier to do the graph.

9. Teacher: Observe what happens when $c$ changes. Do you arrive to the same conjecture? Broaden the interval of analysis for both $a$ and $b$. I wait for your graphs and conclusions.

\section{Discussion}

Regarding the first question (Which types of simulated classroom interactions do the teacher educators propose?), because participants are teacher educators, it is noteworthy that, when they reflect on the students' hypothetical answers, almost two-thirds of them (A2 and A3) do not explore in detail the answers and cannot think on what the student has done (about $66 \%$ of the participants). Moreover, teacher educators should know the importance of the management of interactions to facilitate students' learning. However, a significant percentage of them (about 37\%) propose types of interactions similar to master classes, even following a dogmatic style, in many cases. That is, teachers used to making and analyzing classroom management proposals should be able to analyze students' thinking. In particular, if there are some errors, they should be able to detect their origin and propose teacher interventions that allow students to progress in their learning, which in many cases did not happen. This result may be reasonable with preservice teachers that do not have enough mathematical-didactic knowledge, but it is difficult to explain with teacher educators who should have a broader and deeper knowledge of mathematics teaching than in-service teachers [34]. Moreover, this result is coherent with different research that exposes important imbalances between the theoretical objectives of the training for preservice and in-service teachers and their practices as teachers after the training, for instance $[35,36]$.

There are some reasonable explanations for these results. The first explanation is that the training course for teacher educators did not attain the expected results, due to its limitations in design, management, etc. However, we think that it is more reasonable to consider that these results show the need for specific training for teacher educators, because the self-study training that they obtain from their practice is not enough to design classroom interactions that promote the learning of their students, and this limitation is not solved with a single course like the one implemented. The current agenda of research in the training of teacher educators is moving in this direction; first, it aims to determine the knowledge that teacher educators should have and, then, to design a specific training directed to these teacher educators [2,37].

Our second question was this: Do educators consider the interactional suitability and the ecological suitability in their proposals of simulated dialogues? Despite the fact that specific guidelines were proposed to achieve a high level of students' autonomy (a component of interactional suitability), many educators (with the exception of the $12 \%$ that correspond to the type of intervention I1) did not create interventions according to 
the theoretical tools that were presented in the course, especially those corresponding to I4 $(37 \%)$. They did not create suitable interactions in the classroom with an adequate alternation between students and teacher-considering the enhancement of autonomy and the indicator "Students' conflicts of meaning are noticed and resolved (students' silence, facial expressions, questions are correctly interpreted and an appropriate exploration is conducted)". This result may be reasonable with preservice teachers that do not have enough mathematical-didactic knowledge, but is difficult to explain with teacher educators who should have a deeper knowledge of mathematics teaching [34]. In particular, they should be aware of research on the importance of the teacher-student interactions of the dialogical type for the learning of mathematics [38,39].

In addition, there were no comments about ecological suitability in any of the four types of interventions. However, we indirectly concluded that educators did not consider it because most of their simulated dialogues do not correspond to what the methodological curricular guidelines of Argentina suggest about the interactions that should happen in the classroom. Although some research shows that in-service teachers are often opposed to applying some of the curricular guidelines, it is surprising that this was also observed with teacher educators [40].

\section{Conclusions}

This research was developed in the framework of a teacher training course to relate competences and didactic-mathematical knowledge to the teaching practice, in particular, using tasks of creation of simulated classroom dialogues. The interactional suitability criterion, especially the autonomy component, was implicitly present in the guidelines provided for the creation of simulated dialogues. Despite this, most of the dialogues cannot be considered highly suitable in this component. In addition, most of the types of interventions proposed by educators in the event of wrong conjectures do not correspond to what the curricular orientations and/or lines of Mathematics Education promote. The curricular designs of Argentina suggest a maieutic style of teacher intervention, where the teacher is a mediator of the students' productions. In other words, in their interaction proposals they do not consider the ecological suitability, because they do not follow the curricular guidelines. This result shows that enhancing simulations of didactic interactions in the training of educators, in the case of Argentina, does not generate the same positive results reported by research that tries to foster educational simulations in the context of teacher training [8-11]. In particular, in this study, we did not observe an improvement in the management of interaction, although some elements of this aspect were developed during the training process of the specialization.

Finally, the type of interventions that teacher educators propose is closely related to the level of reflection that teacher educators show about the reasons why their students (preservice teachers) respond to problems one way or another. In this sense, our conclusion is that if the teacher educators perform a detailed reflection and are able to explain what the student could have done, they will more probably propose a management of classroom interaction according to the Argentine curricular guidelines, which promote interaction management with high interactional suitability. Conversely, if the reflection is more superficial (such as those of the teacher educators at levels A2 and A3), it will predictably be difficult for them to manage the classroom interaction following the curricular guidelines.

Our results provide relevant information on: (1) the didactic use of simulated dialogues in teacher training, and (2) the type of dialogues that participants created, an aspect about which there is still little information. Regarding this second aspect, a possible line for further research would be to look for other aspects that condition the types of dialogues proposed by the participating teacher educators, beyond the level of reflection on the reasons why their students (preservice teachers) respond to problems one way or another. 
Author Contributions: Conceptualization, M.P. and V.F.; methodology, A.B., M.P., A.S. and V.F.; validation, A.B., M.P., A.S. and V.F.; formal analysis, A.B., M.P., A.S. and V.F.; resources, M.P.; data curation, M.P.; writing-original draft preparation, A.B., M.P., A.S. and V.F.; writing-review and editing, A.B., M.P., A.S. and V.F. All authors have read and agreed to the published version of the manuscript.

Funding: This research was funded by Ministerio de Ciencia e Innovación, grant number PGC2018098603-B-I00 (MCIU/AEI/FEDER, UE).

Institutional Review Board Statement: Not applicable.

Informed Consent Statement: Informed consent was obtained from all subjects involved in the study.

Data Availability Statement: Not applicable.

Acknowledgments: This research was funded by the Spanish R\&D Projects: PGC2018-098603-B-I00 (MCIU/AEI/FEDER, UE).

Conflicts of Interest: The authors declare no conflict of interest.

\section{References}

1. Robert, A.; Pouyanne, N. Formar formadores de maestros de matemáticas de educación media: ¿por qué y cómo? Educ. Matemática 2005, 17, 35-58.

2. Seckel, M.; Font, V. Competencia reflexiva en formadores del profesorado en matemáticas. Magis 2020, 12, 127-144. [CrossRef]

3. Pochulu, M.; Font, V.; Rodríguez, M. Desarrollo de la competencia en análisis didáctico de formadores de futuros profesores de matemática a través del diseño de tareas. Rev. Latinoam. Investig. Matemática Educ. 2016, 19, 71-98. [CrossRef]

4. Godino, J.D.; Batanero, C.; Font, V. The Onto-Semiotic Approach: Implications for the prescriptive character of didactics. Learn. Math. 2019, 39, 38-43.

5. Costa, C.L.; Agea, J.L.D.; Rojo, A.R.; Rodríguez, L.J.; Arroyo, M.J.L. Practicum y simulación clínica en el Grado de Enfermería, una experiencia de innovación docente. REDU Rev. Docencia Univ. 2014, 12, 421-451.

6. Salas, R.S.; Ardanza, P. La simulación como método de enseñanza y aprendizaje. Educ. Méd. Super. 1995, 9, 3-4.

7. Urra, U.; Sandoval, S.; Irribarren, F. El desafío y futuro de la simulación como estrategia de enseñanza en enfermería. Investig. Educ. Médica 2017, 6, 119-125. [CrossRef]

8. Alvarado, J.C.O.; Acevedo, A.A.C.; Pérez, A.A.D. Simulación como estrategia didáctica en las prácticas de formación docente. Experiencia en la carrera Ciencias Sociales. Rev. Torreón Univ. 2020, 9, 16-28. [CrossRef]

9. Astiz, M.; Vivera, C.; Valdez, G.; Rocerau, M.; Vecino, M.; Pedrosa, M. Profesores de matemática en formación. Simulaciones de prácticas docentes con TICs. In Actas del $4^{\circ}$ Congreso Uruguayo de Educación Matemática; SEMUR, Sociedad de Educación Matemática Uruguaya, Ed.; Sociedad de Educación Matemática Uruguaya: Montevideo, Uruguay, 2012; pp. $135-142$.

10. Orozco Alvarado, J.C.; Díaz Pérez, A.A. La simulación como estrategia didáctica para desarrollar comprensión en la asignatura Historia. Intervención didáctica realizada en Educación Secundaria. Rev. Científica FAREM-Estelí 2017, 21, 4-13. [CrossRef]

11. Sánchez, M. La simulación como estrategia didáctica: Aportes y reflexiones de una experiencia en el nivel superior. Párrafos Geogr. 2013, 12, 55-60.

12. Olanoff, D.; Masingila, J.O.; Kimani, P.M. Supporting Mathematics Teacher Educators' Growth and Development through Communities of Practice. In The Learning and Development of Mathematics Teacher Educators. Research in Mathematics Education; Goos, M., Beswick, K., Eds.; Springer: Cham, Switzerland, 2021; pp. 147-166. [CrossRef]

13. Masingila, J.O.; Olanoff, D.; Kimani, P.M. Mathematical knowledge for teaching teachers: Knowledge used and developed by mathematics teacher educators in learning to teach via problem solving. J. Math. Teach. Educ 2018, 21, 429-450. [CrossRef]

14. Smith, K. So, what about the professional development of teacher educators? Eur. J. Teach. Educ. 2003, 26, 201-215. [CrossRef]

15. Zaslavsky, O.; Leikin, R. Professional development of mathematics teacher educators: Growth in practice. J. Math. Teach. Educ. 2004, 7, 5-23. [CrossRef]

16. Cusi, A.; Morselli, F. Linking theory and practice: Prospective teachers creating fictional classroom discussions. In Proceedings of the 42nd Conference of the International Group for the Psychology of Mathematics Education, Umea, Sweden, 3-8 July 2018; Bergqvist, E., Österholm, M., Granberg, C., Sumpter, L., Eds.; PME: Umea, Sweden, 2018; Volume 2, pp. $323-330$.

17. Arceo-Luna, A.R.; Breda, A.; Font, V.; Páez, D.A. Criterios utilizados por un formador de futuros profesores al reflexionar sobre su práctica. In Investigación en Educación Matemática XXIII; Marbán, J.M., Arce, M., Maroto, A., Muñoz-Escolano, J.M., Alsina, Á., Eds.; SEIEM: Valladolid, Spain, 2019; pp. 161-170.

18. Lloyd, G.M. Preservice teachers' stories of mathematics classrooms: Explorations of practice through fictional accounts. Educ. Stud. Math. 2006, 63, 57-87. [CrossRef]

19. Smith, M.S.; Stein, M.K. Five Practices for Orchestrating Productive Mathematics and Discussions; NCTM: Reston, VA, USA, 2011.

20. Godino, J.D.; Contreras, A.; Font, V. Análisis de procesos de instrucción basado en el enfoque ontológico-semiótico de la cognición matemática. Rech. Didact. Mathématiques 2006, 26, 39-88. 
21. Schwarz, B.; Dreyfus, T.; Hershkowitz, R. Transformation of Knowledge through Classroom Interaction; EARLI-Routledge: London, UK, 2009.

22. Breda, A.; Font, V.; Pino-Fan, L.R. Criterios valorativos y normativos en la Didáctica de las Matemáticas: El caso del constructo idoneidad didáctica. Bolema 2018, 32, 255-278. [CrossRef]

23. Breda, A.; Pino-Fan, L.; Font, V. Meta didactic-mathematical knowledge of teachers: Criteria for the reflection and assessment on teaching practice. EURASIA J. Math. Sci. Technol. Educ. 2017, 13, 1893-1918. [CrossRef]

24. NCTM. Principles and Standards for School Mathematics; National Council of Teachers of Mathematics: Reston, VA, USA, 2000.

25. García Marimón, O.; Morales Maure, L.; Diez-Palomar, J.; Durán González, R.E. Evaluación de secuencias de aprendizaje de matemáticas usando la herramienta de los Criterios de Idoneidad Didáctica. Bolema 2021, 35, 1047-1072. [CrossRef]

26. Morales-Maure, L.; Durán-González, R.E.; Pérez-Maya, C.; Bustamante, M. Hallazgos en la formación de profesores para la enseñanza de la matemática desde la idoneidad didáctica. Experiencia en cinco regiones educativas de Panamá. Rev. Incl. 2019, $6,142-162$.

27. Seckel, M.J. Competencia en Análisis Didáctico en la Formación Inicial de Profesores de Educación General Básica con Mención en Matemática. Ph.D. Thesis, University of Barcelona, Barcelona, Spain, 2016.

28. Breda, A. Características del análisis didáctico realizado por profesores para justificar la mejora en la enseñanza de las matemáticas. Bolema 2020, 34, 69-88. [CrossRef]

29. Cobb, P.; Confrey, J.; di Sessa, A.; Lehrer, R.; Schauble, L. Design experiments in educational research. Educ. Res. 2003, 32, 9-13. [CrossRef]

30. Ruthven, K.; Hofmann, R. A case study of epistemic order in mathematics classroom dialogue. PNA 2016, 11, 5-33.

31. Boukafri, K.; Civil, M.; Planas, N. A teacher's use of revoicing in mathematical discussions. In Language and Communication in Mathematics Education: International perspectives; En, J., Moschkovich, D., Wagner, A., Bose, J., Rodrigues Mendes, J., Schütte, M., Eds.; Springer: Dordrecht, The Netherlands, 2018; pp. 157-169. [CrossRef]

32. Seckel, M.J.; Breda, A.; Sanchez, A.; Font, V. Criterios asumidos por profesores cuando argumentan sobre la creatividad matemática. Educ. E Pesqui. 2019, 45, e211926. [CrossRef]

33. Sánchez, A.; Font, V.; Breda, A. Significance of creativity and its development in mathematics classes for preservice teachers who are not trained to develop students' creativity. Math. Ed. Res. J. 2021. [CrossRef]

34. Zopf, D. Mathematical Knowledge for Teaching Teachers: The Mathematical Work of and Knowledge Entailed by Teacher Education. Ph.D. Thesis, The University of Michigan, Ann Arbor, MI, USA, 2010.

35. Charles-Pézard, M.; Butlen, D.; Masselot, P. Professeurs des Ecoles Débutants Enseignant les Mathématiques en ZEP: Quelles Pratiques? Quelle Formation? La Pensée Sauvage: Grenoble, France, 2012.

36. Vergnes, D. Effets d'un stage de formation en géométrie sur les pratiques d'enseignements d'école primaire. Rech. Didact. Des Mathématiques 2001, 21, 99-122.

37. Pascual, M.I.; Montes, M.; Contreras, L.C. The Pedagogical Knowledge Deployed by a Primary Mathematics Teacher Educator in Teaching Symmetry. Mathematics 2021, 9, 1241. [CrossRef]

38. Bakker, A.; Smit, J.; Wegerif, R. Scaffolding and dialogic teaching in mathematics education: Introduction and review. ZDM 2015, 47, 1047-1065. [CrossRef]

39. Díez-Palomar, J.; Chan, M.C.E.; Clarke, D.; Padrós, M. How does dialogical talk promote student learning during small group work? An exploratory study. Learn. Cult. Soc. Interact. 2021, 30, 100540. [CrossRef]

40. Crecci, V.M.; Fiorentini, D. Gestão do currículo de Matemática sob diferentes profissionalidades. Bolema 2014, 28, 601-620. [CrossRef] 